\title{
NASMA; SUSTAINABLE CLIMATE-RESPONSIVE SCHOOLS FOR SYRIAN REFUGEES IN LEBANON
}

\author{
K. NAJJAR, B. MADI \& A. NOURALDEEN \\ Department of Architecture and Design, American University of Beirut, Lebanon.
}

\begin{abstract}
The paper discusses research that concerns itself with the design explorations of high performance structural and climatic systems. It also examines their efficient and low-cost application techniques in refugee facilities. Initially, the paper presents a survey of the current conditions of refugee schools in Lebanon. The survey highlights the need for alternative design strategies in the provision of environmentally friendly educational facilities with low-cost yet adequate learning conditions. Considering the current conditions, the premise is set that required design strategies call for an integrated strategic approach. This is to promote sustainable development models as post-disaster responses. The "Nasma" project is then taken as a case study that exemplifies a sustainable pilot project as a post-disaster response. It is an educational unit developed and implemented in Lebanon by the author in collaboration with a team from Transsolar climate engineers led by Christian Frenzel. It therefore represents a paradigm of integrated architectural and environmental design strategies taking into considering the complex socio-political context of refugee settlements in Lebanon's Bekaa Valley. The project aims to provide visual, air, thermal and acoustic comfort. It also integrates innovative structural systems and construction methods that allow the school to be rapidly deployed and relocated. Strategies that aim towards social impact include using local materials and engaging the community in the building process. Finally the paper concludes by assessing the actual performance of the structure as a replicable post-disaster response.

Keywords: alternative design strategies, high performance structural and climatic systems, integrated strategic approach, post-disaster responses, sustainable development models.
\end{abstract}

\section{INTRODUCTION}

The influx of Syrian refugees fleeing as of March 2011 has been described as one of the largest refugee crises since World War II [1]. Among the hosting countries, the burden has been the heaviest on Lebanon. The refugees hosted in Lebanon amount to almost $26 \%$ of its total population, the largest ratio among the hosting countries [1]. Lebanon's weak governance system and failure to create a centralised response has resulted in fragmented micro-responses. Refugee camps established later into the crisis, termed as "post-emergency" phase camps should seek to achieve a respectable standard of social and economic life. However, in the case of Lebanon, they are similar to emergency phase camps five years into the crisis [1]. Meanwhile, the refugees have settled in 1730 dispersed localities throughout the country [2]. Therefore, emerging actors such as local governments, NGOs, international organisations, academics and the private sector have risen to fill in the development gap. The government's reluctance to address the issue as a long-term one is partly influenced by the previous experience with Palestinian refugee settlements, which were supposed to be temporary, resulted in over 500,000 Palestinians still residing today in Lebanon [1]. The increase of population implicates heavy burdens on the inadequate infrastructure and disadvantages the existing impoverished Lebanese communities. Lebanon's conflicted history has thus led the government to reject almost every shelter alternative model proposed by international and relief organisations [1]. Therefore, relief offered to Syrian refugees in Lebanon can be described as a matrix of ad-hoc responses. They are often also culturally inappropriate and not sustainable. Moreover, international organisations have been criticised for their standardised relief mechanisms which are 
applied to natural disasters and refugee displacement similarly [3]. On the other hand, this paper aims to present a contextual yet replicable prototype as a post-disaster response.

Based on the situation described above, this paper addresses the need for alternative design strategies to provide environmentally friendly facilities with low cost yet adequate comfort parameters. As the struggle to meet the basic needs of refugees goes on, so does the comprehensive expansion of the educational infrastructure to absorb school-aged children. The Lebanese Ministry of Education and Higher Education's (MEHE) funded public schools are currently equipped to accommodate only 300,000 of the total Lebanese student population of over 900,000. This renders the public school system incapable of absorbing the influx of over 400,000 school-aged Syrian refugee children seeking education in Lebanon [4]. Accordingly, the case of the "Nasma" school prototype by Professor Karim Najjar from the American University of Beirut (AUB) in collaboration with a team from Transsolar [5] climate engineers led by Christian Frenzel [6] is presented. The case illustrates the expanded role of the architect from design to mediation in complex environments. In this case, the architect mediates the design proposal among the various stakeholders involved to manifest Nasma as a unique sustainable response. This paper elaborates on Nasma's adopted strategic integrated approach in terms of targeting educational facilities as the main issue and accordingly defining the objectives. After an initial observation of the current situation, it appeared that the majority of the relief responses are concerned with shelter. The decision to target educational facilities was thus prioritised as it would facilitate the continuation of refugee children's academic and professional paths once the conflict is over. This would minimise many socio-economic problems pertaining to the upcoming generation of Syrians.

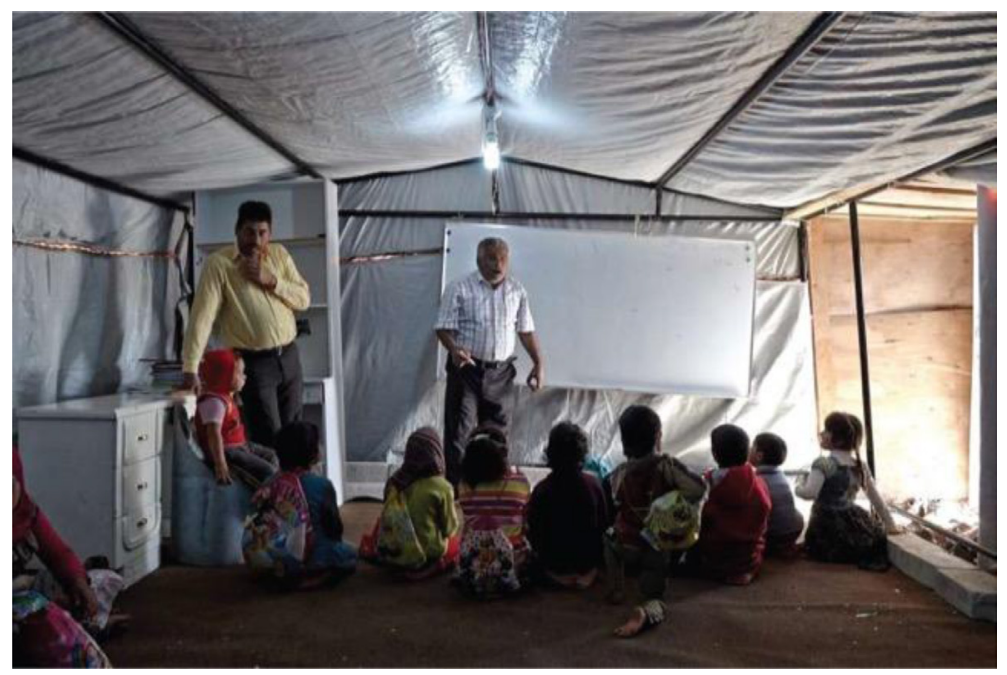

Figure 1: Example of a make-shift school inside a refugee camp in the Bekaa.

\section{NASMA'S DESIGN RESEARCH}

\subsection{Survey of current educational spaces}

Lebanon's Bekaa valley is home to one of the Lebanon's most deprived communities [7]. It also hosts the largest number of school-aged refugee children [4]. After identifying educa- 
tional facilities as the main issue, the Bekaa valley was targeted as the starting intervention site. In terms of project planning the following phases were set: (1) site survey, (2) design research, (3) concept, (4) implementation and (5) testing. The site survey consists of research on the climatic conditions and their influence on learning ability which will be explained in this section. The site survey was completed through observation and semi-structured interviews with students, operators and the surrounding community.

Currently, makeshift schools found inside settlement areas are made of wooden studs covered in plastic sheets. Separate classrooms are divided by lightweight panels. They are often set on thin concrete slabs which are invasive to the agricultural land in Bekaa. In terms of temperature and radiation, cold and hot temperatures in summer and winter challenge a healthy learning environment, leading to frequent cancelation of classes. Conventional heating and cooling devices are often inefficient, costly and rarely available. As for the air quality the confined spaces of refugee schools lack proper ventilation which increases the $\mathrm{CO}_{2}$ emission in the classrooms drastically. Exposure to $\mathrm{CO}_{2}$ can result in drowsiness, eye irritation and inability to concentrate. The light conditions in most refugee classrooms are poor. Darkness or glare in the classrooms has a negative impact on the learning environment. The acoustic conditions are of utmost relevance for educational spaces as this parameter has a significant effect on the receptiveness of students. Students and teachers are often distracted due to the infiltration of noise. The sites have no or poor waste management systems which contaminate the earth and water. A school prototype called Ghatta [8] was recently developed by the Centre of Civic Engagement and Community Service at AUB in collaboration with the Kayany NGO [9]. They have implemented four schools so far and have provided better educational spaces. However, their schools still lack parameters of thermal comfort, insulation and sound proofing.

\subsection{Identifying potential stakeholders and beneficiaries}

In order to forsee the functional operation of Nasma, the following stakeholders were contacted as potential partners. Consideration of these future potential partners is part of the integrated strategy, which aims to develop a fully functional model beyond its physical implementation. Due to their experience in the operation of educational facilities the Kayany foundation was needed as a partner to administer the school and the field coordination of the child protection program. Kayany will also be responsible for collecting and reporting data from the field on a daily basis. As for the project management and coordination, the American University of Beirut's (AUB) Centre for Civic Engagement and Community Service (CCECS) has been identified as the partner responsible for the program coordination and facilitating trainings. The AUB- CCECS will administer the coordination of expert trainings. The Iqraa Association will train teachers in implementing curriculum and classroom management techniques. The design and engineering stakeholders are the author Karim Najjar in collaboration with German Transpolar Climate Engineering. Their task is to carry out all the design and engineering services including site supervision. Involving partners and stakeholders from the different required sectors, ensures the success of the project. This exemplifies a critical aspect of the strategic integrated approach and the extension of the role of the architect. As for the beneficiaries, the Nasma school prototype hosts up to 25 students. As refugee school students usually attend half day shifts, this would allow for the education of 50 students. 


\subsection{Objectives}

After having identified educational facilities as the main issue the following three integrated objectives were set to ensure a sustainable model as a result.

\subsubsection{Objective 1: Adequate learning conditions}

After having surveyed the current make-shift educational spaces within the camps as well as the Kayany schools, ensuring good learning conditions was set as the first objective. In order to increase the learning and concentration capacity of the students the following indicators were set: (1) thermal comfort, (2) air comfort, (3) visual comfort and (4) acoustic comfort. Thermal comfort is crucial due to the Bekaa's hot arid summers and harsh snowy winters. As for the air comfort, a ventilation system is needed to keep the students' attention at an optimal level. Visual comfort allows for the better receptiveness of educational material written on white boards as well as those hung on the wall. Acoustic comfort provides the students with a calm and relaxing environment. The climatic design concept in section 3.1 explains how this objective is met. Furthermore, indicators for adequate learning were tested and the findings are shown in section 3.4 .

\subsubsection{Objective 2: Environmentally friendly}

The second objective towards sustainability was set as providing an environmentally friendly design. The indicators to measure this objective were set as: (1) using local materials, (2) re-usable materials, (3) low energy systems and (4) ensuring a small building footprint. These indicators are measures to reduce the carbon footprint as much as possible and thus decrease negative environmental impact. Therefore, minimizing transportation distance of material was considered. Local materials include wood and sand bag canvas which also helps the revenue cycle remain within the local community. Re-used materials include using agricultural waste as insulation as well as existing earth to fill the sandbags which provide thermal mass. This is further elaborated in section 2.4.

\subsubsection{Objective 3: Socially responsive}

Due to the complex socio-political context in which the Nasma project aimed to be placed, the third objective was set as having a socially responsive design. This would be insured by the following parameters: (1) using a participatory process, (2) a relocatable design and (3) adaptable use. Participation in implementation is necessary to increase the users' sense of stake in the space which has high implications on the proper usage and maintenance of the space. Their participation was ensured through involving them in the building process. The space must also be adaptable and therefore should have an unobstructed unit space that could cater to different functions such as a community centre or recreational centre for its surrounding community. This is important due to the lack of recreational and gathering spaces available to the refugees.

\subsection{Design research}

The design research begins with exploring high-performance structural systems. The team investigated vernacular techniques using local materials in an effort to adapt the shelters for extreme weather. Earth ducts were built using Horde units that maximized temperature exchange with the earth. Sand bags provide a good solution for thermal comfort in a low cost and low tech way. Sand bags were filled with existing earth on site and stacked to form adobe walls used as a base for the building envelope. As for the frame, traditional frame structures 
and envelopes made of herds skin which have high insulation properties were explored for extreme weather. The design of roof vents to complement the traditional tent structures were investigated to accommodate hearths as a source of heat that would drive the ventilation mechanism inside the shelter. Solar chimneys were built using HVAC ducts painted black for maximum solar gain. In addition to the tent structures, RF-structures, which require no central supports and are easily assembled and dissembled were looked into as a viable cost effective deployable system, particularly suitable for rapid constructions of temporary structures. The temporary aspect is important for the social acceptance of the structures within the Lebanese community as anything pertaining to permanence would have received a negative outlook. Therefore the design research builds on the objectives.

In addition to the exploration of vernacular techniques and local materials their relative prices in the market were investigated. The costs were divided into four main categories: (1) the ground works, (2) wooden framing system, (3) sand bags and (4) insulation and waterproofing. It appeared that the mostly costly category was the wood, while the insulation cost was almost negligible as it consisted of reused agricultural waste.

\section{NASMA'S PROPOSAL ELEMENTS}

\subsection{Climatic design concept}

The climatic design concept combines several passive strategies to fulfil the second objective. Passive strategies were integrated into the three main components of the prototype: the ground, floor and roof systems. Starting with the ground, the negative pressure inside the classroom sucks air from the duct openings inside the class. Air is sucked into the tubes from outside, passes through the geothermal maze underground and goes into the classroom. Colder air is driven inside the unit in the summer and warmer air in winter due to the median mean temperature of the earth surrounding the ducts being exchanged with the passing air.

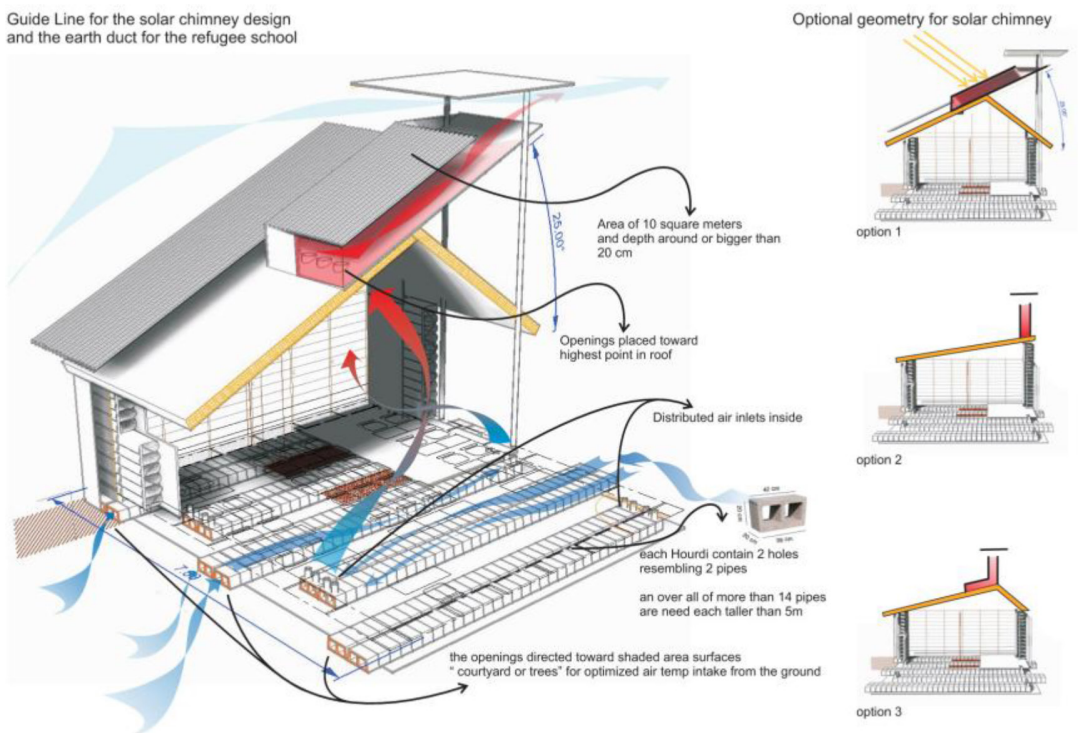

Figure 2: The climatic design concept. 
Geothermal ducts are distributed underneath the school floor. The roof complements the ground system with a solar chimney. To be able to suck the tempered air from these tubes, the solar chimney is positioned on the south oriented side of the class roof. The sun heats the air inside the chimney thus driving the hot air upward and creating negative pressure inside the classroom unit. As for the wall system, earth bags filling the wooden wall section act as humidity dampeners due to the physical properties of the earth. Excess humidity inside the classroom is absorbed by the earth walls, and when it dries, water evaporates from the earth to dehumidify the internal space again. The sand bags also contribute to the wall section's thermal mass to achieve a consistent interior temperature. Deep window openings provide shading during high sun angles, and lets in indirect sun during early morning and winter low sun angles for direct solar heat gain.

\subsection{Simulations}

In order to predict the effectiveness of the expected climatic strategies, the thermal and light conditions were simulated. In order to simulate the thermal conditions the software TRNSYS was used by the Transsolar engineers. A base case design was set as a rectangular concrete room unit. This base case design was tested for its thermal comfort. A second iteration was made by adding earth walls with exterior insulation instead of the concrete walls. In extreme winter and summer days the second iteration showed an offset of two degrees (to the better) during operation time. Also, a third iteration was made by adding a selective shading strategy and roof insulation. The selective shading element provides shading during peak temperature times and lets in direct solar heat gain in early morning and cold winter days. The roof insulation was simulated as ten centimetres. Testing of the third iteration resulted in an offset of four degrees in the temperature in the extreme summer day peak hours. The fourth iteration was done by adding geothermal ducts. This last iteration enhanced two degrees in temperature. Therefore the final compilation of the second, third and fourth iterations showed an enhancement of six degrees during extreme summer days and two degrees during cold winter days.

Similarly, day light simulations were done using a combination of iterations with the software grasshopper Galapagos engine. It simulated combinations between number of windows, height, width of window and depth. The measures reached 500 lux as annual average illumination during operation time and coherent levels throughout the area of the classroom unit.

\subsection{Implementation}

During implementation the team faced several challenges were faced. One of the challenges was the ability to implement the prototype in the Bekaa due to difficulty in attaining land. This is due to several stakeholders' apprehension towards implementing a pilot prototype. The prototype was thus implemented outside the Bekaa region, in village Burj Kalaway in Southern Lebanon. No discrepancy was witnessed between the iterations done for the Bekaa and the implemented prototype in the South. Also, some financial challenges were faced during implementation. The wooden frame was slightly more costly than expected due to the unavailability of skilled workers and therefore the need for trials which increased cost. 
The implementation is divided according to the prototype's three main components: (1) ground, (2) walls, and (3) roof system. The ground system comprises of earthwork and foundations. The wall system is comprised of sandbags, insulation, framing structure and plastering. The roof system includes the framing structure, insulation and solar chimney. The earthwork consists of site preparation (Fig. 3), levelling (Fig. 3), earth duct assembly (Fig. 4) and earth duct outlets (Fig. 5). Sand bags acting as foundations are laid (Fig. 6) and are covered with plastic sheets for waterproofing (Fig. 7). As for the wall system, the sand bags require soil testing (Fig. 8), then they are filled and closed (Fig. 9). The framing structure is done by producing eco-beams made out of wood rectangular frames braced with PPR pipes (Fig. 10). The frames are then assembled to form the larger framing system (Fig. 11). After the frame structure is erected, it is filled with sandbags which act as thermal mass (Fig. 12). The sandbags are connected to the frames using barbed wire to resist wind loads. The roof structure is then assembled along with the installation of the solar chimney (Fig. 14). The insulation used to insulate the roof was made up of agricultural waste found on site (Fig. 16). The final step of plastering is achieved by mixing the plaster and then testing it on a wall section (Fig. 17). The process of plastering and smoothening is then completed on all the wall faces. This is done in collaboration with the community to enhance their participatory engagement and thus their sense of ownership (Fig. 19).

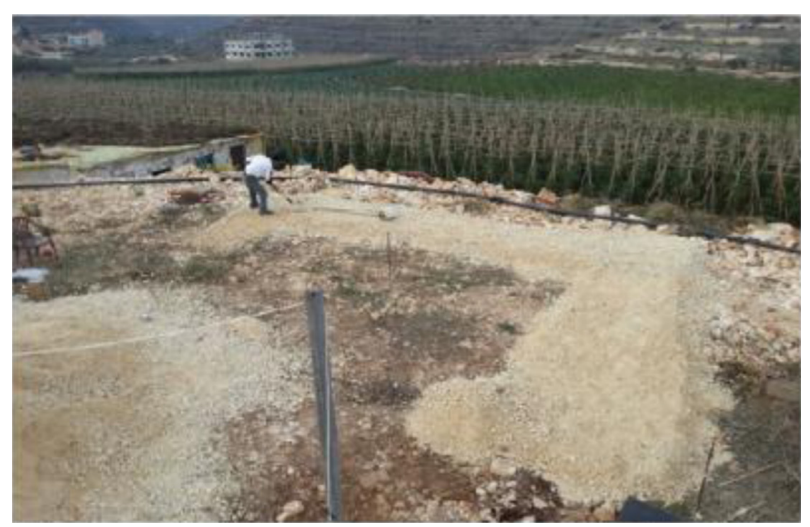

Figure 3: Site preparation \& leveling.

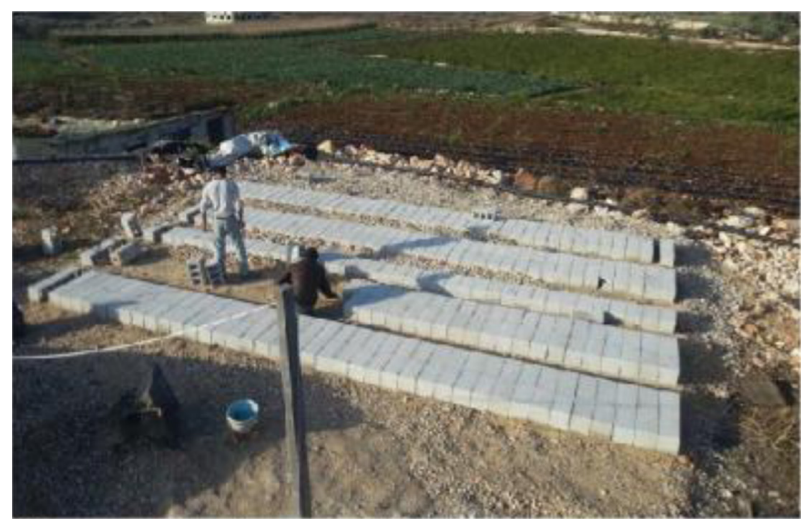

Figure 4: Assembling earth ducts. 


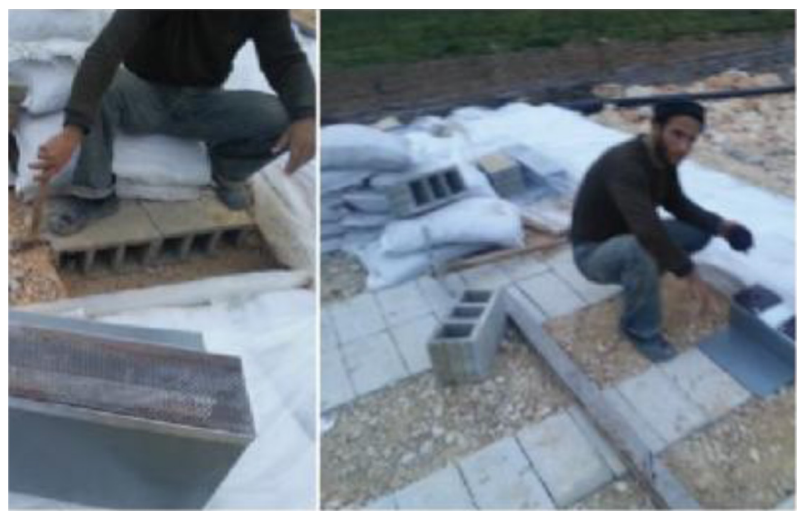

Figure 5: Earth duct outlets.

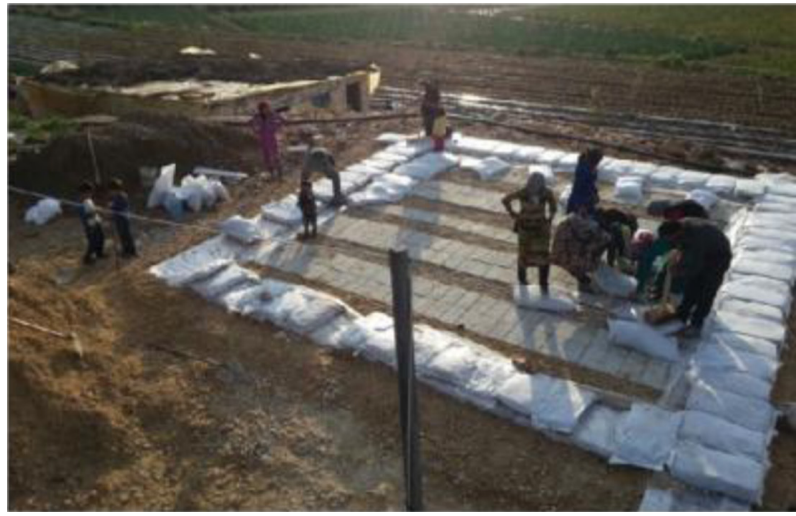

Figure 6: Assembling footings.

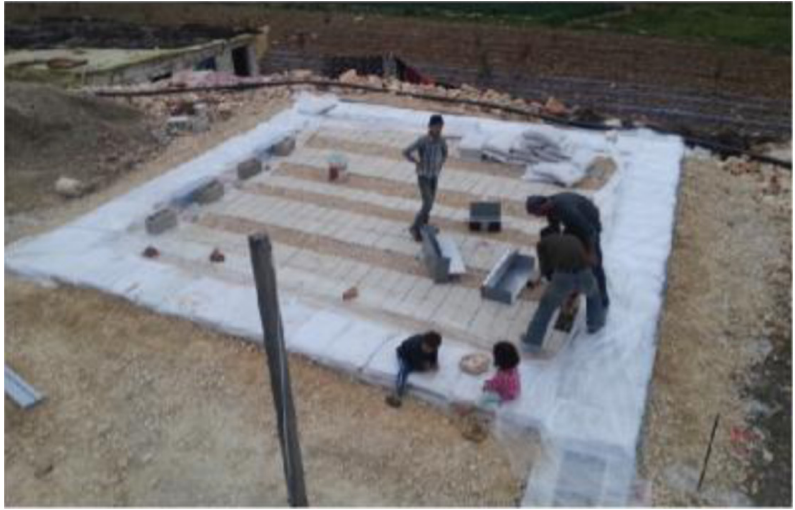

Figure 7: Waterproofing. 


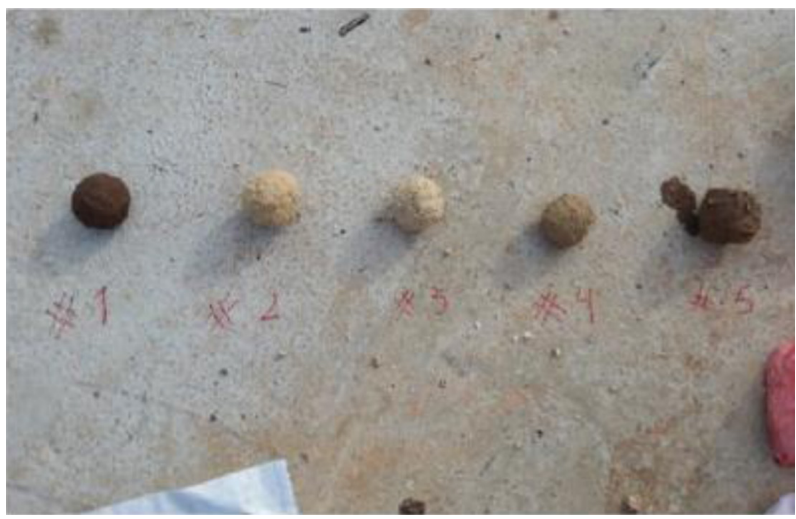

Figure 8: Soil testing for sandbags.

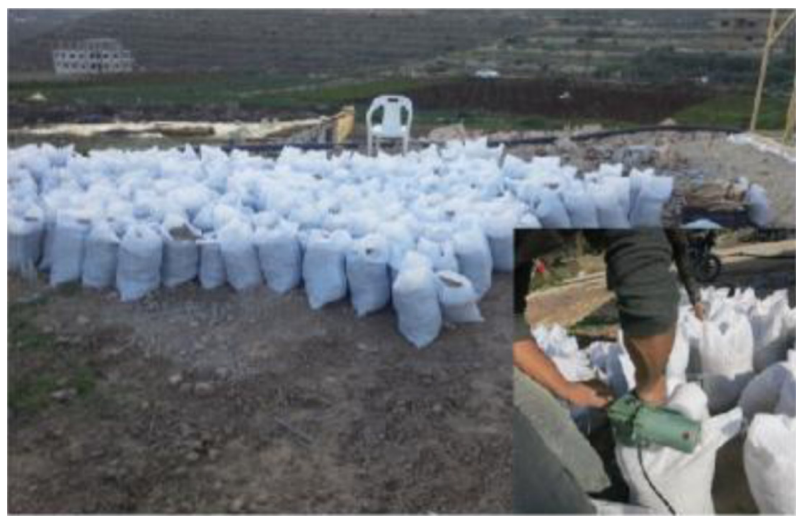

Figure 9: Sand bag filling.

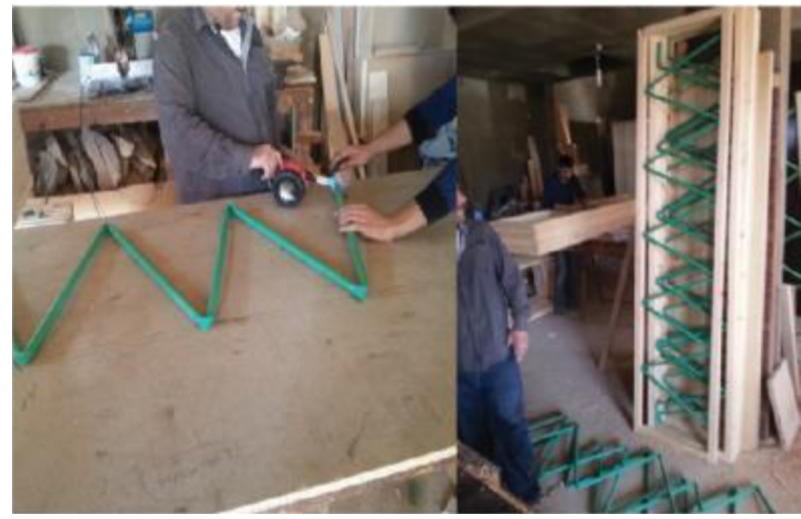

Figure 10: Eco-beam production. 


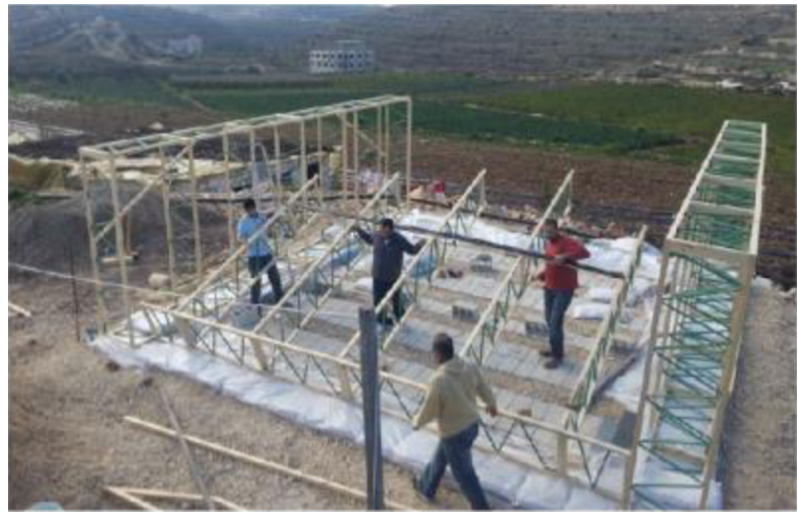

Figure 11: Assembling Eco-beams.

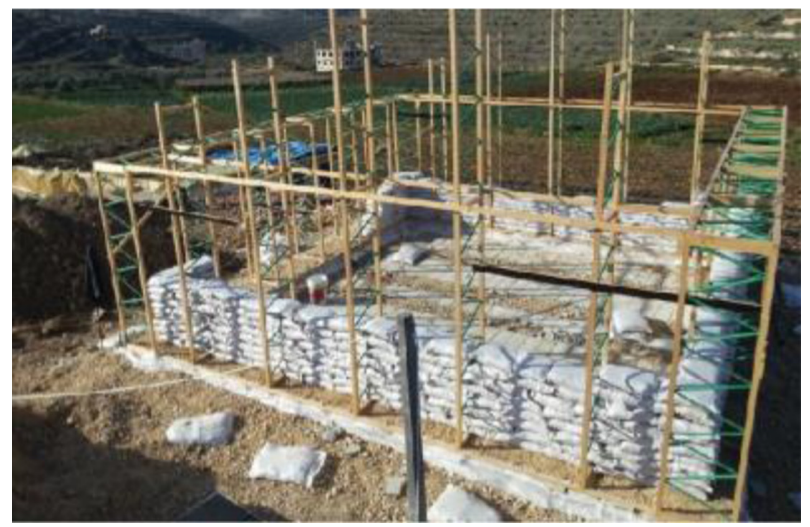

Figure 12: Sand bag stacking.
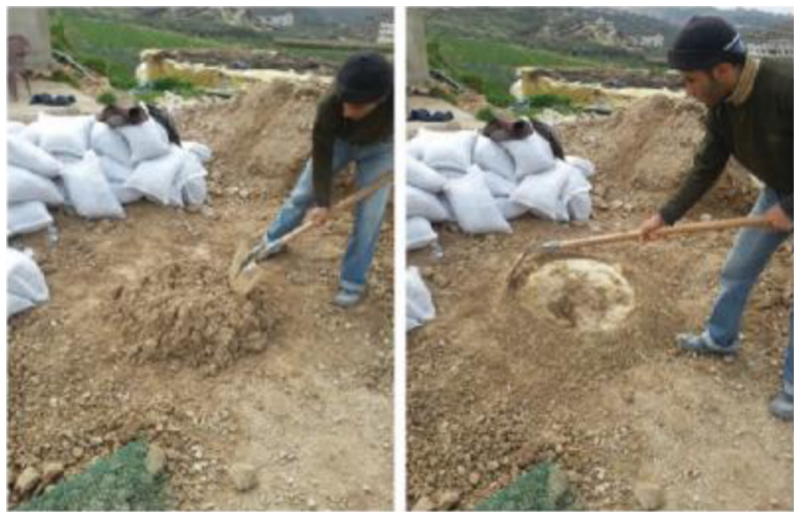

Figure 13: Testing the plaster. 


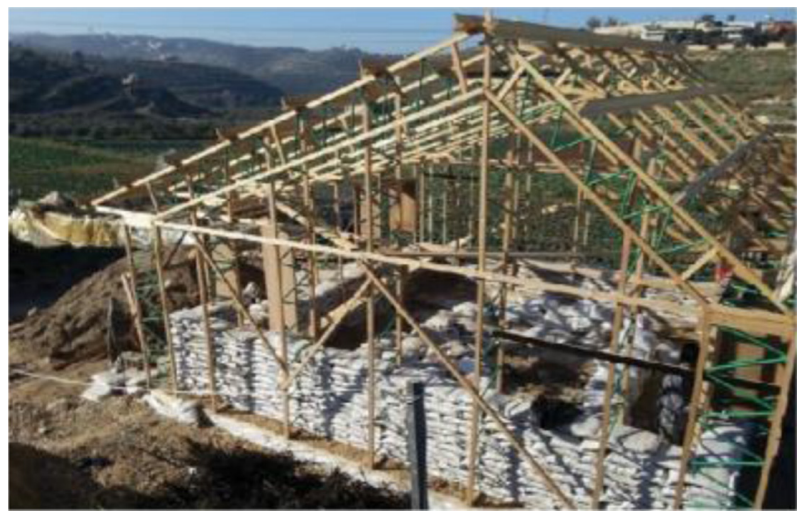

Figure 14: Assembling roof structure.

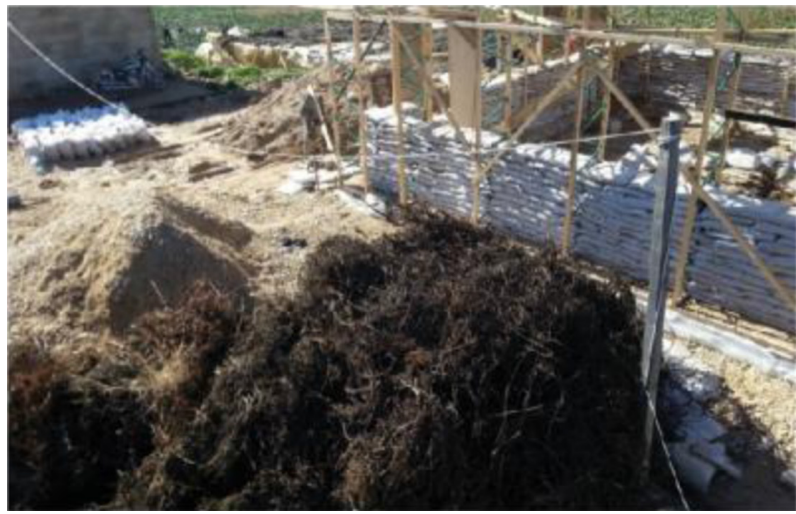

Figure 15: Collecting insulation material.

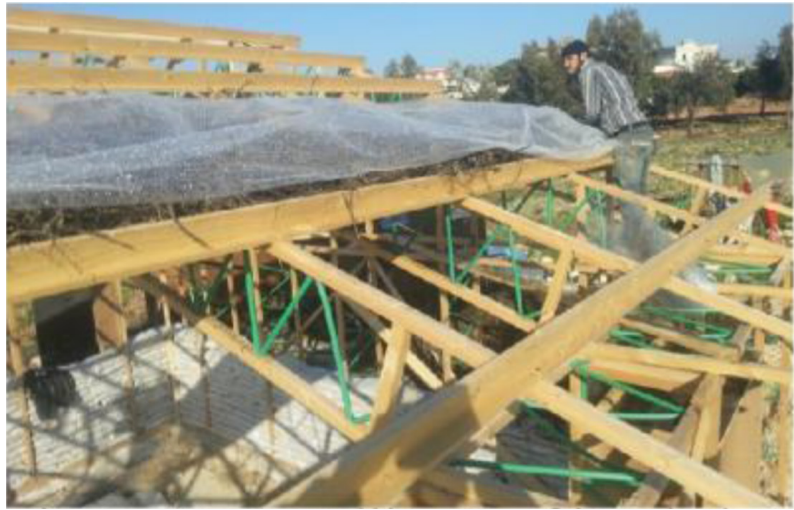

Figure 16: Installing roof insulation. 


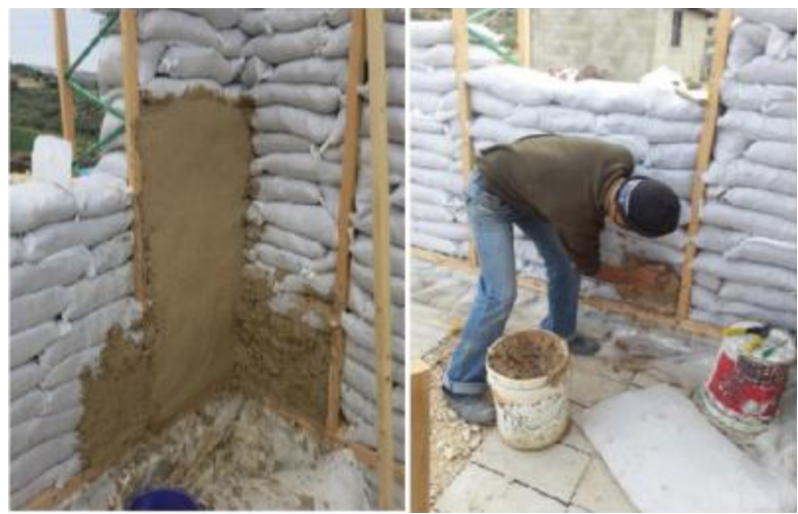

Figure 17: Testing the plaster.

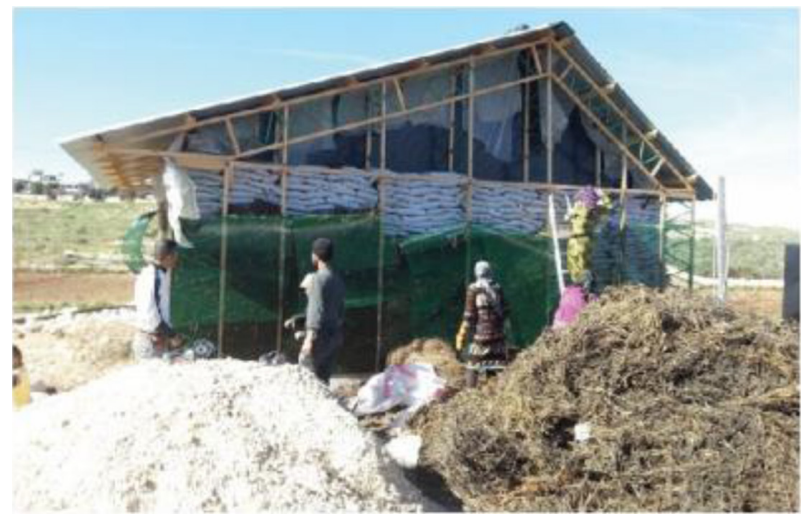

Figure 18: Filling with insulation.

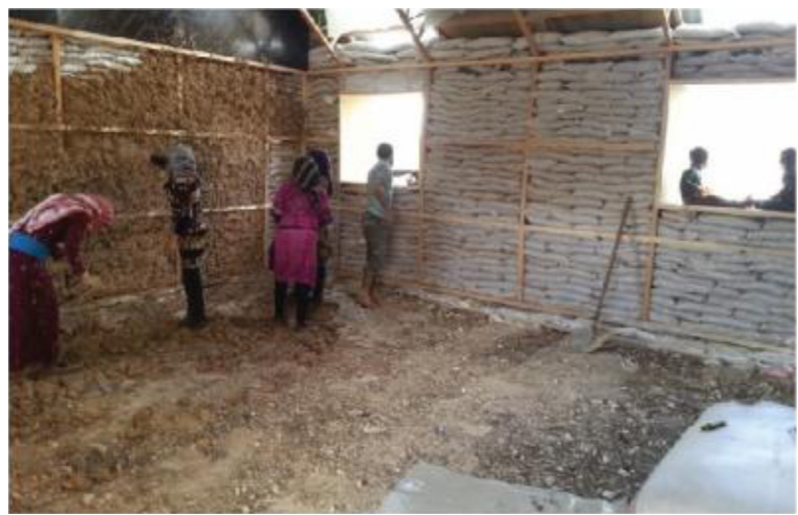

Figure 19: Refugees plaster \& help. 


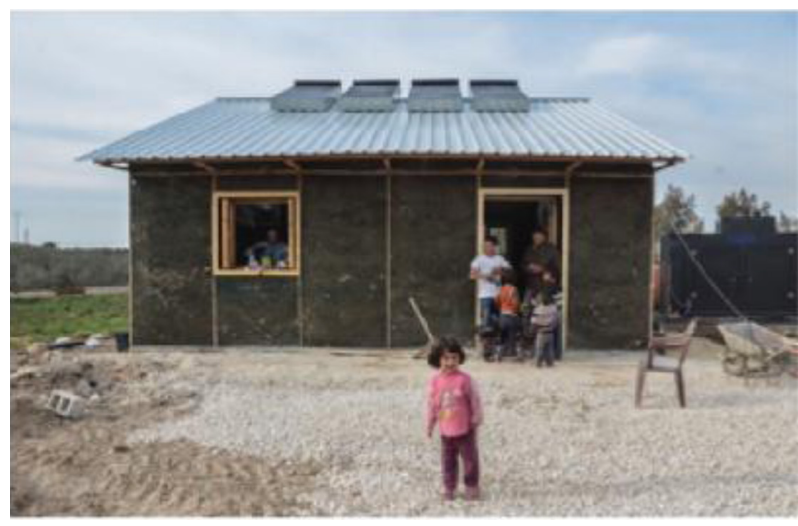

Figure 20: Completed school unit.

\subsection{Testing}

As for the testing of the prototype's efficiency, the following indicators defining the objective of good learning conditions were used. The thermal comfort was tested by measuring temperature and relative humidity. The air comfort was tested by measuring air velocity. The visual comfort was tested by measuring the light in the room. A temperature comparison inlets shows that the exterior temperature reaches 35 degrees in extreme summer days. The measured results inside the classroom "near geothermal outlets" show that temperature during night and day time is a straight line around 25 degrees. This means that on extreme hot days a temperature difference of 10 degrees was achieved. The thermal enhancement of six degrees is witnessed when testing in the middle of the space. As a conclusion, all the systems are working very well and the earth thermal mass is dampening the night and day temperature and preserving an equilibrium state of temperature inside all the time. The outside insulation and roof insulation is emphasising on this effect.

As for the humidity, outside in summer nights its range is $90 \%$, while inside it was in the range of $70 \%$, and thus lowered, and as an average the humidity as well dampened. This is a combination of both the temperature that was achieved and also using the earth as a humidity absorbing material. A measurement of air velocity shows how air is circulating form ground outlets to the solar chimney inlets in average speed of $1 \mathrm{~m} / \mathrm{s}$ by the enhanced stack effect. Day light measurements through the 4 windows and the northern skylights, show coherent, symmetrical and diffused daylight levels were achieved, with no direct sunlight inside that creates glare. Even the room corners had a daylight level more than 500 lux which is ideal for studying. Through all of these passive strategies we were able to provide comfort levels inside the classroom through adequate daylight, temperature and humidity levels.

\section{CONCLUSIONS}

The design research, proposal and implementation show that it is indeed possible to provide adequate and sustainable educational spaces for refugees. Therefore, the approach can provide a solution in Lebanon's fragmented array of responses. In conclusion the approach is successful due to its flexibility in site conditions and available materials and resources. This is since the design research is focused on low-tech and low-cost effective strategies, which 
are then implemented in the construction phase. Several potential development and improvement opportunities were brought to light during the implementation phase. Some of which are the possibility to reduce the complexity of the framing systems, this would also reduce the work force and cost needed. Another possibility is modifying the laying technique of the geothermal blocks by laying them in a trench instead of meticulously aligning them so that their internal voids are linear. Also, the material chosen for the sandbags, could have been further explored. The plastic material was not practical due to its slippery quality. Such observations, if taken into consideration for a future prototype could have a considerable effect on the total construction time, cost and effort needed. The total cost of the prototype summed up to be 9000 Euros, which could be reduced to 6000 Euros. The reduction of the construction time from three weeks is a critical aspect as it also affects the surrounding Lebanese community's acceptance of the structure in their territories. The comfortable environment inside the space encourages the development of other models and facilities in a similar approach. This is possibly due to the temporary light feel of the structure which has not been rejected by the surrounding. The integration of environmental as well as aesthetic guidelines from the start of the project, guarantees a sustainable and comprehensive result. The prototype has inspired international collaborations and partnerships to develop the approach and model further.

\section{REFERENCES}

[1] UN-HABITAT, No place to stay, September 2015.

[2] UNHCR, Syrian Refugees in Lebanon, 2015.

[3] Aleinikoff, T.A., From Dependence to Self-Reliance: Changing the Paradigm in Protracted Refugee Situations, Washington, DC, 2015.

[4] Ghanem, E., Lebanon's schools do double-duty to educate both Syrian, Lebanese students, October 30, 2015

[5] Refugee School Bekaa Valley. Online. http://www.transsolar.com/projects/refugeeschool-bekaa-valley

[6] Transsolar Energietechnik GmbH. Online. http://www.transsolar.com/offices/stuttgart

[7] Abdul Samad, Z., Millennium Development Goals: Lebanon Report 2008, 2008.

[8] American University of BEirut. Centre for Civic Engagement and Community Service. Bringing Education to Informal Tented Settlements. Online. https://www.aub.edu.lb/ ccecs/Pages/Education.aspx

[9] Kayany foundation. Ghata. Online. http://www.kayany-foundation.org/tag/ghata/ 